\title{
Method for Rainfall Rate Estimation with Satellite based Microwave Radiometer Data
}

\author{
Kohei Arai \\ Graduate School of Science and Engineering \\ Saga University, Saga City \\ Japan
}

\begin{abstract}
Method for rainfall rate estimation with satellite based microwave radiometer data is proposed. A method to consider the geometric relationship of the observed ice particles and microwave radiometer in the estimation of precipitation is shown, and its validity is shown by comparing it with precipitation radar data on the ground. Observations at high altitudes, such as ice particles, differ greatly in the location of the observation point projected on the ground surface and in the upper troposphere where the observations exist. This effect was insignificant when the precipitation was small because ice particles were often absent, but it was found that the effect was large when the precipitation was large. In other words, the proposed method is effective and effective for Advanced Microwave Scanning Radiometer (AMSR) data in Houston, which was shown as an example of a highly developed convective rain cloud with an In the case of Kwajalein, the effect is insignificant. In addition, the proposed method requires an assumption of ice particle height, and it is necessary to make assumptions based on climatic values. In addition, microwaves in the $89 \mathrm{GHz}$ band, which are considered to be sensitive to ice particles, are not only sensitive to ice particles, so it must be taken into account that they are also affected by the presence of non-ice particles.
\end{abstract}

Keywords-Rainfall rate estimation; Advanced Microwave Scanning Radiometer: AMSR; geometric relation

\section{INTRODUCTION}

Spencer et al., Liu, and Curry proposed a precipitation estimation algorithm using a microwave radiometer Special Sensor Microwave / Imager (SSM / I) [1]. In addition, Liu modified the algorithms such as the beam filling effect (Beam filling effect) to these algorithms, and the microwave radiometer Earth Observation Satellite System: EOS: AMSRE mounted on the Earth observation satellite Advanced Earth Observing Satellite: ADEOS II has the same sensor as the AMSR itself [2]. Therefore, AMSR and AMSR-E can use the same estimation algorithm.

Current precipitation of AMSR-E The Japan Aeronautics Exploration Agency: JAXA standard product uses a precipitation estimation algorithm by Liu [3]. In precipitation estimation using microwave radiation, the observed brightness temperature in the frequency band around $18 \mathrm{GHz}$ and 89 $\mathrm{GHz}$ is generally used [4]. That is, the absorption attenuation of microwaves in the frequency band around $18 \mathrm{GHz}$ and the scattering by ice particles in the frequency band around 89 $\mathrm{GHz}$ are taken into account [5].
Considering the vertical structure of a rain cloud accompanied by strong precipitation, such a rain cloud has a liquid layer up to $0^{\circ}$ altitude (freezing altitude) at the bottom, and a mixture of solid (ice particles) and liquid (rain). It consists of a layer and the top layer consisting only of solids (ice particles). Compared to stratified clouds, convective clouds with strong updrafts generally produce more ice particles due to the updrafts, cause strong rainfall, and have large spatiotemporal changes [6].

The brightness temperature of the $89 \mathrm{GHz}$ band microwave is dominated by the scattering of ice particles in the mixed layer and the top layer, and the brightness temperature of the $18 \mathrm{GHz}$ band microwave is dominated by the absorption and attenuation due to the raindrops in the lower layer. Therefore, the microwaves in the $89 \mathrm{GHz}$ band and the $18 \mathrm{GHz}$ band have different altitudes of sensitivity to precipitation [7].

The microwave radiometer AMSR-E on board the Aqua satellite (the second satellite of EOS satellite series) has a footprint in the $18 \mathrm{GHz}$ band of $16 \times 27 \mathrm{~km}$ (scanning $\times$ traveling direction), which is too coarse to observe local rain due to convective clouds such as cumulonimbus clouds . For this reason, local precipitation estimation was attempted using a high-frequency band with a relatively small footprint. However, as described above, ice particles sensitive to the high-frequency band exist at high altitudes. It is necessary to make it consistent with the surface precipitation.

In this study, the author attempted to estimate precipitation from the effect of scattering from ice particles in clouds using $89 \mathrm{GHz}$ data of AMSR-E. As a result, it was found that there was a displacement between the estimated precipitation and the distribution of precipitation measured by ground-based precipitation radar.

The next section, related research works are reviewed followed by proposed method with theoretical background. Then, some experimental works are described together with some results. After that, conclusion and some remarks are described together with future research works.

\section{RELATED RESEARCH WORKS}

Evaluation of Marine Observation Satellite: MOS-1 Microwave Scanning Radiometer: MSR data in field experiments was made for microwave radiometer performance evaluation [8]. Advanced Microwave Scanning Radiometer: AMSR is proposed and the preliminary study is made [9] 
together with specification and design of the instrument [10]. On the other hand, antenna pattern correction and Sea Surface Temperature: SST estimation algorithms for AMSR is proposed [11] together with potential capabilities of the instrument [12].

Meanwhile, simultaneous estimation of sea surface temperature, wind speed and water vapor with AMSR-E data based on improved simulated annealing is proposed [13]. Also, correction of the effect of relative wind direction on wind speed derived by AMSR is proposed and validated [14]. Precipitation estimation using AMSR data considering geometric relationship between observation target and radiometer is proposed [15]. Nonlinear optimization based SST estimation methods with remote sensing satellite based Microwave Scanning Radiometer: MSR data is proposed and validated [16].

As for rainfall rate estimation, method for estimation of rain rate with Rayleigh and Mie scattering assumptions on the Z-R relationship for different rainfall types is proposed and evaluated its accuracy [17]. On the other hand, comparison between Rayleigh and Mie scattering assumptions for Z-R relation and rainfall rate estimation with Tropical Rainfall Measuring Mission: TRMM/Precipitation Radar: PR data is proposed [18]. Detecting algorithm for rainfall area movement based on Kalman Filtering is also proposed [19]. Meanwhile, reconstruction of cross section of rainfall situations with precipitation radar data based on wavelet analysis is proposed and well reported [20].

\section{PROPOSED METHOD}

The JAXA standard algorithm described above, which is used for AMSR-E standard products, is based on the Liu algorithm (hereinafter referred to as the standard algorithm). This standard algorithm does not take into account the altitude of the object to be observed or the orientation of the sensor mounted on the satellite. There is a report that clarifies the effect of the radiative transfer equation on the upward luminance temperature from the surroundings on the footprint of interest, taking into account the incident angle of 53 degrees, such as SSM / I. Some reports have evaluated the effects of slant paths on microwave radiometers.

\section{A. Observation Configuration}

In this study, the author propose a method to consider the observation configuration in the estimation of precipitation. In other words, the shift caused by observation using microwaves in the $89 \mathrm{GHz}$ band was attributed to the altitude of the target and the direction of observation, and the author proposed precipitation estimation taking this into account. Fig. 1 shows geometric relation between AMSR and observation target of clouds.

Emitted electronic and magnetic wave from the observation area is propagated with incidence angle through a rainy atmosphere including ice particles in clouds and raindrops reached to the microwave radiometer onboard satellite. In this observation configuration, there is a displacement between actual observation area and apparent observation area. Therefore, this displacement causes same estimation errors in precipitation and rainfall rate estimations.

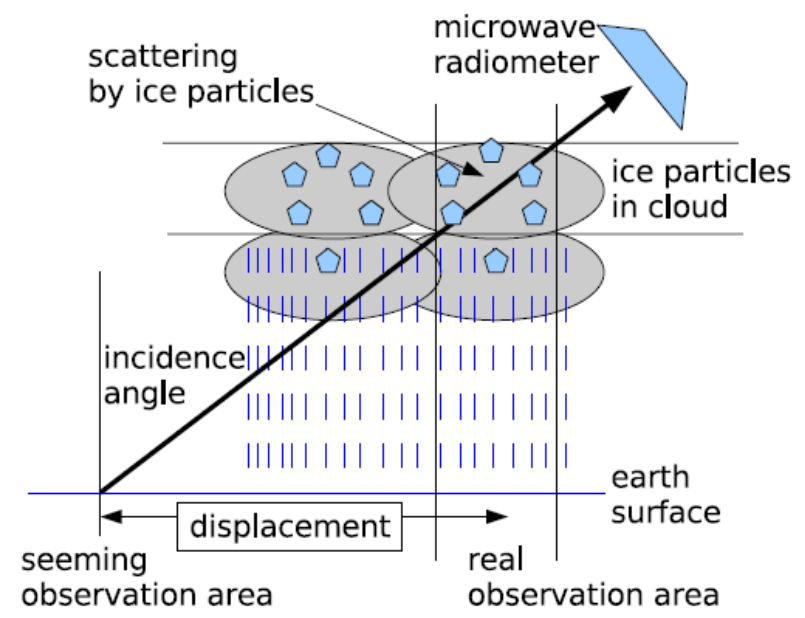

Fig. 1. Geometric Relation between AMSR and Observation Target of Clouds.

Assuming that the difference between the observation points due to the observation configuration depends on the average altitude at which ice particles exist (called the average height of ice particles), the average height of ice particles, the incident angle and azimuth of observation by the microwave radiometer, and the apparent Between the actual observation point and the difference between the observation point and the latitude / longitude is expressed as follows,

lat, $=l_{a t}{ }^{\prime}+D \cos \theta_{a}$

lon $=$ lon' $+D \sin \theta_{a}$

$\mathrm{D}=\mathrm{H} / \tan (90-\theta \mathrm{i})$

where lat, lon is the latitude and longitude of the actual observation point, lat, lon is the latitude and longitude of the apparent observation point, $D$ is the distance of horizontal deviation, $H$ is the average ice particle height, $\theta a$ is the observation azimuth, $\theta i$ is the observed incident angle.

\section{B. Conventional Method}

Precipitation estimation algorithm by Liu (The relationship between precipitation $R$ and microwave index $f$ ) was expressed using the beam-filling effect.

$\mathrm{R}=\alpha \mathrm{f}^{\beta}$

$\alpha$ and $\beta$ are called beam-filling factors and are factors that depend on the footprint size of the sensor. The footprint of the $19 \mathrm{GHz}$ band of SSM / I is less than $50 \mathrm{~km}, \alpha=10.6$ and $\beta=$ 1.621. AMSR's $18 \mathrm{GHz}$ band footprint is about half that of SSM / I, and $\alpha=8.25, \beta=1.88$, respectively. Microwave index $f$ is represented as follows,

$\mathrm{f}=\left(1-\mathrm{D} / \mathrm{D}_{0}\right)+2\left(1-\mathrm{PCT} / \mathrm{PCT}_{0}\right)$

$\mathrm{D}=\mathrm{T}_{\mathrm{B} 18 \mathrm{~V}}-\mathrm{T}_{\mathrm{B} 18 \mathrm{H}}$

$\mathrm{PCT}=1.818 \mathrm{~T}_{\mathrm{B} 5 \mathrm{~V}}-0.818 \mathrm{~T}_{\mathrm{B} 5 \mathrm{H}}$

The first term on the right-hand side represents microwave radiation absorption by raindrops, and the second term represents the effect of microwave scattering by ice particles contained in rain clouds. $D$ is the difference between vertical and horizontal polarization (Depolarization), $P C T$ is the polarization-corrected temperature. 
$T_{B}$ is the luminance temperature observed by the sensor, the subscript number is frequency, the subscript $V$ is vertical polarization, and the subscript $H$ is horizontal polarization. $D_{0}$ and $P C T_{0}$ are thresholds at the beginning of rain, respectively, and a monthly reference table is created using the observed brightness temperature and sea surface temperature of 36.5 $\mathrm{GHz}$.

$D$ and PCT are compatible with SSM / I, when used in AMSR and AMSR-E as follows,

$\mathrm{D}_{\mathrm{SSM} / \mathrm{I}}=-0.14+0.903 \mathrm{D}_{\mathrm{AMSR}}$

$\mathrm{PCT}_{\mathrm{SSM} / \mathrm{I}}=2.2+0.996 \mathrm{PCT}_{\mathrm{AMSR}}$

Since the beam filling factors $\alpha$ and $\beta$ correspond to the 18 $\mathrm{GHz}$ observation data, the physical quantity obtained by this method is the instantaneous surface precipitation that is averaged within the footprint of the $18 \mathrm{GHz}$ observation microwave. By the way, the footprint of the $18 \mathrm{GHz}$ observation microwave is $15.7 \times 27.4$ [km] (scanning direction $\times$ traveling direction).

\section{Proposed Method}

In order to fix the beam filling factors $\alpha$ and $\beta$ that are indicators of raindrops, we estimate precipitation using only the scattering of ice particles, taking into account the dynamic range of $f$.

The effects of raindrop absorption and ice particle scattering are used for microwave precipitation estimation, but by removing the raindrop absorption element $(18 \mathrm{GHz})$ therefrom, precipitation that considers only ice particle scattering is taken into account. Precipitation can be estimated (precipitation using only the observed brightness temperature in the $89 \mathrm{GHz}$ band). Then, equation (3) can be replaced to equation (6).

\section{$\mathrm{f}=4\left(1-\mathrm{PCT} / \mathrm{PCT}_{0}\right)$}

Calculate the deviation within a certain area and the average height of ice particles based on the average height of ice particles and the correlation coefficient between actual precipitation and scattered precipitation of ice particles. The correlation coefficient is defined as follows,

$R=\frac{\sum_{N}\left(P_{t}-P_{t^{\prime}}\right)\left(P_{i}-P_{i^{\prime}}\right)}{\sqrt{\sum_{N}\left(P_{t}-P_{t^{\prime}}\right)^{2}} \sqrt{\sum_{N}\left(P_{i}-P_{i^{\prime}}\right)^{2}}}$

where $N$ is the number of data, $P t$ is the actual precipitation, $P i$ is the scattered ice particle precipitation. Also, $P t^{\prime}$ and $P i^{\prime}$ are mean of $P t^{\prime}$ and $P i^{\prime}$, respectively.

When the correlation reaches the peak, calculate the deviation within a certain area and the average height of ice particles. Also, precipitation radar observations and AMSR-E observations estimate gaps and ice particle average altitudes using spatiotemporal matchup data.

\section{EXPERIMENT}

\section{A. Data used}

As the actual precipitation, the author estimate the surface precipitation obtained from ground precipitation radars and rain gauges. As the actual precipitation, the surface precipitation (L2A52, NASA TRMM Ground-based Instrument Data) obtained from ground precipitation radars and rain gauges is used. The radar sites are Houston, Texas (N29.472 [degree], W95.079 [degree]) as the subtropical zone and Kwajalein, N8.720 [degree], E167.740 [degree] as the tropical zone, Marshall Islands).

The precipitation from ground-based precipitation radar is referred to as "actual precipitation", and the estimated precipitation due to ice particle scattering is referred to as "ice particle scattering precipitation". In order to take into account the effects of seasonal fluctuations, etc., and to improve the reliability of the analysis results, the year in Houston in 2008 was assumed. (Houston in July and Kwajalein in September).

\section{B. Area in Concern}

Since the estimation accuracy of ice particle scattered precipitation is not very good, the difference from the actual precipitation is remarkable. However, the distribution of precipitation in a certain area of ice particle scattered precipitation and actual precipitation shows similar characteristics. By the optimization method using the distribution, it is possible to examine the difference between the actual precipitation and the ice particle scattering precipitation. The problem with this method is that it must be assumed that the shift within the constant area used is uniform. Therefore, it is assumed that the ice particle height within a certain area is also uniform. The smaller the constant area used here, the better, but if it is too small, it will not find the distribution.

In the precipitation estimation on January 10, 2008, the analysis was divided into four areas as shown in Fig. 2.

As a result, the estimated ice crystal flat altitudes showed different values as shown in Fig. 3. For this reason, it can be said that the smaller the fixed area used here is, the more preferable it is. However, if it is too small, it becomes impossible to find a distribution pattern. In addition, the probability that a cloud of the same pattern is generated increases, and it is likely that a local optimal solution is likely to occur. For these reasons, it is difficult to determine the optimal range, so in this study this fixed area was used as the measurement range for ground-based precipitation radar. Correlation coefficients for the designated four areas as a function of scattering altitude is shown in Fig. 3.

The fixed area used in this study is the measurement range of ground precipitation radar. In this study, it is assumed that the cause of the slip is the observation configuration. The actual cause of this shift is also caused by the parallel movement by the wind and the falling time of precipitation. In this study, we assumed the average height of ice particles and used it as a variable. The time when the correlation coefficient between the actual precipitation and the ice particle scattered precipitation is the highest is the time when the distribution is the best.

As an example, Fig. 4 shows the correlation coefficient when the average height of ice particles in the data of Houston on July 2, 2007 was changed. 


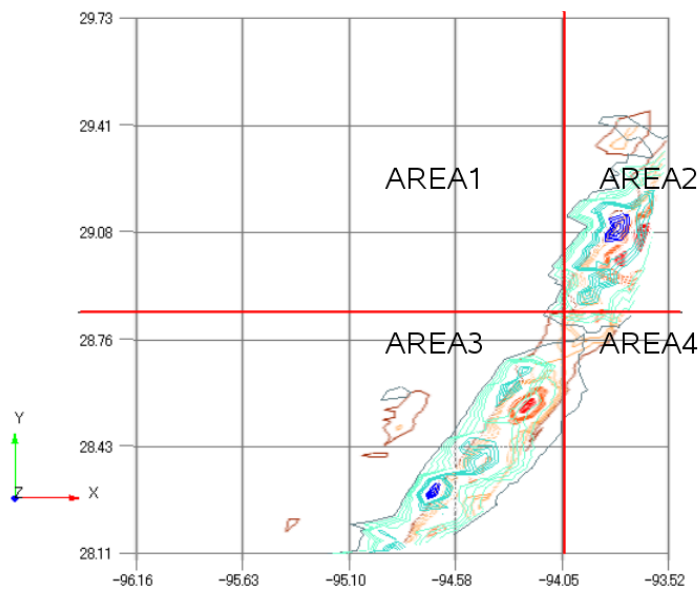

Fig. 2. Estimated Rainfall Rate with AMSR-E Data Acquired on January 10 2008 for Four Divided Areas.

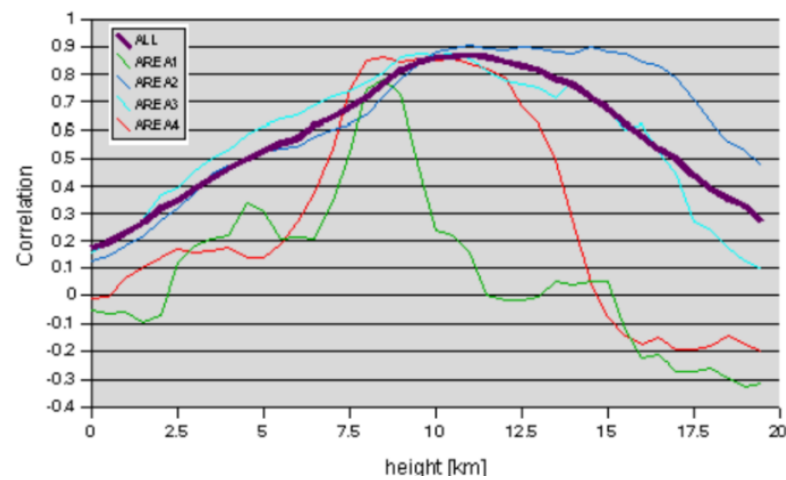

Fig. 3. Correlation Coefficients for the Designated Four Areas as a Function of Scattering Altitude.

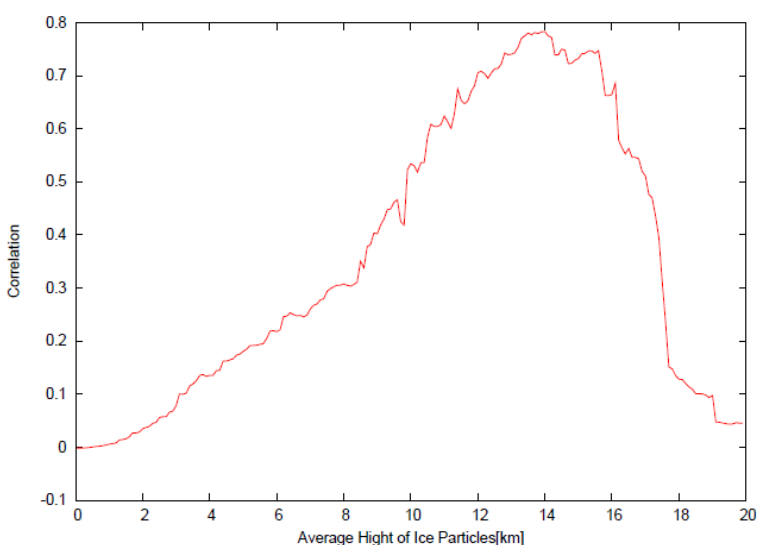

Fig. 4. Relation between Average Height of Ice Particles and Correlation between Actual and Estimated Precipitation for the Observation Data of July

$$
22007 .
$$

It can be said that it is possible to estimate the altitude at which ice particles are present from the geometric relationship showing the peak of the correlation coefficient. Fig. 4 shows the correlation between the change in the average ice particle height and the actual precipitation distribution in the observation data on July 2, 2007. The horizontal axis is the assumed ice particle height and the vertical axis is the correlation coefficient between the actual precipitation and the ice particle scattering precipitation.

\section{Estimated Results}

In this study, the gap between precipitation radar observation and AMSR-E observation was estimated using spatiotemporal matchup data, and the average height of ice particles was estimated. Table I shows the results for Houston in July 2007, and Table II shows the results for Kwajalein in September 2007.

In the table, the number of data indicates the number of constant regions of AMSR-E for which precipitation was estimated, and $\mathrm{Rt}(\mathrm{mm} / \mathrm{hr}$ ) is the average precipitation in the observation area. Also, Orig.R shows the correlation coefficient between the actual precipitation and the estimated precipitation when the height of the ice particles is not taken into account, and Max.R shows the correlation coefficient when taking that into account. $\mathrm{H}$ and $\mathrm{D}$ indicate the height of the ice particle level and the amount of deviation from the position showing the maximum correlation with the observation position. N / A indicates not applicable. In this case, the estimated precipitation is close to 0 , which means that it is excluded from consideration.

TABLE. I. DISTANCE BETWEEN OBSERVED LOCATION AND THE LOCATION THAT SHOWS HIGHEST CORRELATION OF ESTIMATED PRECIPITATION, AND ESTIMATED MEAN ALTITUde OF ICE PARTICleS (HOUSTON DATA)

\begin{tabular}{|c|c|c|c|c|c|c|c|}
\hline $\begin{array}{l}\text { Data } \\
\text { No. }\end{array}$ & Date & $\begin{array}{l}\text { No. of } \\
\text { Data }\end{array}$ & $\begin{array}{l}\mathrm{Rt}(\mathrm{mm} / \mathrm{h} \\
\mathrm{r})\end{array}$ & $\begin{array}{l}\text { Orig } \\
\mathrm{R}\end{array}$ & $\begin{array}{l}\text { Max } \\
\mathrm{R}\end{array}$ & $\begin{array}{l}\mathrm{H}(\mathrm{km} \\
)\end{array}$ & $\begin{array}{l}\mathrm{D}(\mathrm{km} \\
)\end{array}$ \\
\hline 1 & $7 / 2$ & 676 & 0.24 & 0 & 0.78 & 14 & 0.18 \\
\hline 2 & $7 / 4$ & 627 & 9.03 & 0.34 & 0.64 & 10.5 & 0.15 \\
\hline 3 & $7 / 5$ & 599 & 0.51 & 0.06 & 0.23 & 3.5 & 0.04 \\
\hline 4 & $7 / 6$ & 741 & 0.8 & 0.06 & 0.66 & 13.5 & 0.17 \\
\hline 5 & $7 / 7$ & 1032 & 0 & 0.06 & 0.06 & 0 & 0 \\
\hline 6 & $7 / 7$ & 541 & 0 & N/A & N/A & 0 & 0 \\
\hline 7 & $7 / 9$ & 661 & 0 & -0.01 & -0.01 & 0 & 0 \\
\hline 8 & $7 / 9$ & 562 & 0 & N/A & N/A & 0 & 0 \\
\hline 9 & $7 / 11$ & 730 & 0 & N/A & N/A & 0 & 0 \\
\hline 10 & $7 / 12$ & 730 & 0 & N/A & N/A & 0 & 0 \\
\hline 11 & $7 / 13$ & 638 & 0 & N/A & N/A & 0 & 0 \\
\hline 12 & $7 / 14$ & 574 & 0 & N/A & N/A & 0 & 0 \\
\hline 13 & $7 / 16$ & 793 & 0.03 & 0.12 & 0.43 & 6 & 0.08 \\
\hline 14 & $7 / 16$ & 543 & 0 & N/A & N/A & 0 & 0 \\
\hline 15 & $7 / 18$ & 450 & 3.19 & 0.14 & 0.61 & 19 & 0.24 \\
\hline 16 & $7 / 20$ & 627 & 0.12 & 0.02 & 0.69 & 11 & 0.14 \\
\hline 17 & $7 / 21$ & 628 & 0 & N/A & N/A & 0 & 0 \\
\hline 18 & $7 / 22$ & 684 & 0 & N/A & N/A & 0 & 0 \\
\hline 19 & $7 / 23$ & 1091 & 0 & 0.09 & 0.63 & 12.5 & 0.16 \\
\hline 20 & $7 / 23$ & 543 & 0 & N/A & N/A & 0 & 0 \\
\hline 21 & $7 / 25$ & 676 & 0.13 & 0.15 & 0.51 & 8 & 0.1 \\
\hline 22 & $7 / 25$ & 471 & 0.75 & 0.05 & 0.47 & 11.5 & 0.12 \\
\hline 23 & $7 / 27$ & 684 & 2.33 & 0.16 & 0.68 & 17.5 & 0.22 \\
\hline 24 & $7 / 27$ & 712 & 0 & 0.11 & 0.21 & 0.5 & 0.18 \\
\hline 25 & $7 / 28$ & 720 & 0.68 & 0.13 & 0.21 & 2 & 0.03 \\
\hline 26 & $7 / 30$ & 568 & 0 & N/A & N/A & 0 & 0 \\
\hline
\end{tabular}


TABLE. II. DISTANCE BETWEEN OBSERVED LOCATION AND THE LOCATION THAT SHOWS HIGHEST CORRELATION OF ESTIMATED PRECIPITATION, AND ESTIMATED MEAN ALTITUDE OF ICE PARTICLES (KWAJALEIN DATA)

\begin{tabular}{|l|l|l|l|l|l|l|l|}
\hline $\begin{array}{l}\text { Data } \\
\text { No. }\end{array}$ & Date & $\begin{array}{l}\text { No. of } \\
\text { Data }\end{array}$ & $\begin{array}{l}\text { Rt }(\mathrm{mm} / \mathrm{h} \\
\mathrm{r})\end{array}$ & $\begin{array}{l}\text { Orig } \\
\mathrm{R}\end{array}$ & $\begin{array}{l}\text { Max } \\
\mathrm{R}\end{array}$ & $\begin{array}{l}\mathrm{H}(\mathrm{km} \\
)\end{array}$ & $\begin{array}{l}\mathrm{D}(\mathrm{km} \\
)\end{array}$ \\
\hline 1 & $9 / 1$ & 931 & 0.75 & 0.28 & 0.51 & 11.6 & 16.26 \\
\hline 2 & $9 / 1$ & 939 & 0.29 & 0.33 & 0.56 & 8.6 & 12.06 \\
\hline 3 & $9 / 3$ & 909 & 0.51 & 0.22 & 0.43 & 9 & 12.62 \\
\hline 4 & $9 / 3$ & 1146 & 0.5 & 0.01 & 0.35 & 13 & 18.23 \\
\hline 5 & $9 / 4$ & 1070 & 0.14 & 0.06 & 0.16 & 11.2 & 15.7 \\
\hline 6 & $9 / 5$ & 902 & 0.22 & 0.04 & 0.39 & 14.8 & 20.75 \\
\hline 7 & $9 / 5$ & 174 & 0.29 & 0.04 & 0.76 & 13.4 & 18.79 \\
\hline 8 & $9 / 6$ & 404 & 0.2 & 0.05 & 0.06 & 2.6 & 3.65 \\
\hline 9 & $9 / 6$ & 1041 & 0.17 & $\mathrm{~N} / \mathrm{A}$ & $\mathrm{N} / \mathrm{A}$ & 0 & 0 \\
\hline 10 & $9 / 8$ & 919 & 0.48 & 0.33 & 0.45 & 3 & 4.21 \\
\hline 11 & $9 / 10$ & 1002 & 0.55 & 0.35 & 0.62 & 9.2 & 12.9 \\
\hline 12 & $9 / 12$ & 897 & 0.24 & 0.17 & 0.22 & 17.2 & 24.11 \\
\hline 13 & $9 / 12$ & 956 & 0.16 & 0.02 & 0.02 & 2.8 & 3.93 \\
\hline 14 & $9 / 13$ & 1018 & 0.15 & 0.43 & 0.47 & 3.8 & 5.33 \\
\hline 15 & $9 / 13$ & 1231 & 0.17 & 0.12 & 0.13 & 7.4 & 10.37 \\
\hline 16 & $9 / 15$ & 1045 & 4.29 & 0.73 & 0.78 & 5.8 & 8.13 \\
\hline 17 & $9 / 15$ & 958 & 0.48 & 0.43 & 0.53 & 10.4 & 14.58 \\
\hline 18 & $9 / 17$ & 936 & 0.25 & -0.01 & 0.06 & 7.2 & 10.09 \\
\hline 19 & $9 / 19$ & 1000 & 5.89 & 0.54 & 0.75 & 15.2 & 21.31 \\
\hline 20 & $9 / 20$ & 1071 & 2.18 & 0.73 & 0.78 & 12.2 & 17.1 \\
\hline 21 & $9 / 21$ & 992 & 0.14 & 0.07 & 0.33 & 9 & 12.62 \\
\hline 22 & $9 / 22$ & 1003 & 1.43 & 0.42 & 0.5 & 9 & 12.62 \\
\hline 23 & $9 / 22$ & 1042 & 0.16 & 0.16 & 0.19 & 9.4 & 13.18 \\
\hline 24 & $9 / 24$ & 966 & 0.2 & 0.26 & 0.29 & 3.4 & 4.77 \\
\hline 25 & $9 / 26$ & 945 & 0.3 & 0.16 & 0.28 & 13 & 18.23 \\
\hline 26 & $9 / 26$ & 723 & 0.71 & 0.34 & 0.6 & 11 & 15.42 \\
\hline 27 & $9 / 28$ & 1130 & 0.43 & 0.29 & 0.47 & 10 & 14.02 \\
\hline 28 & $9 / 28$ & 936 & 0.41 & 0.34 & 0.51 & 9.2 & 12.9 \\
\hline 29 & $9 / 29$ & 381 & 0.15 & N/A & N/A & 0 & 0 \\
\hline 30 & $9 / 29$ & 915 & 0.1 & N/A & N/A & 0 & 0 \\
\hline 31 & $9 / 30$ & 204 & 1.78 & 0.09 & 0.74 & 20 & 28.04 \\
\hline
\end{tabular}

According to Tables I and II, data with high average precipitation in the observation area are assumed assuming the average height of ice particles. The number of relationships has improved significantly. This is because the distribution becomes clearer as the precipitation increases. Conversely, for data with low precipitation, there is no characteristic of the distribution of precipitation, so no improvement in the correlation coefficient is observed. This may be due to the absence of ice particles in rain clouds when precipitation is low.

The details of the data on July 2, 2007 in Houston are shown below as examples showing the distribution and deviation of each data and the ice particle level and altitude. First, Fig. 5 shows the distribution of actual precipitation and ice particle scattering precipitation. From Fig. 5, it can be seen that the distribution of actual precipitation and the scattering of ice particle precipitation roughly agree, but a displacement of about 10 to $20 \mathrm{~km}$ occurs. Observation in the $89 \mathrm{GHz}$ band has a small footprint (5.9 $\mathrm{km}$ in the direction of observation), and this shift leads to a large estimation error in precipitation. Fig. 6 shows the AMSR-E horizontal observation direction of the data corresponding to Fig. 5. From Fig. 6, it can be seen that the direction of the deviation coincides with the horizontal observation direction of AMSR-E.

Fig. 7 shows the distribution of the actual precipitation and the scattered precipitation of ice particles assuming the average height of ice particles of $14.0 \mathrm{~km}$. The assumption of $14.0 \mathrm{~km}$ was obtained from Table I, but even in the tropics, the 0 degree altitude is about 5 or $6 \mathrm{~km}$, and convective precipitation exceeding $10 \mathrm{~km}$ is rare, so it is not very realistic.

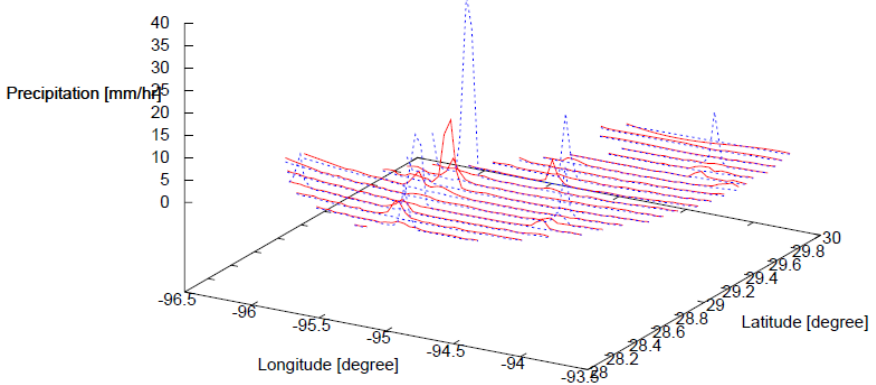

Fig. 5. Distribution of Actual Precipitation (Solid Line) and Estimated Precipitation (Doted Line) with Scattering Due to Ice Particles. Each Line Corresponds to Observation Scan.

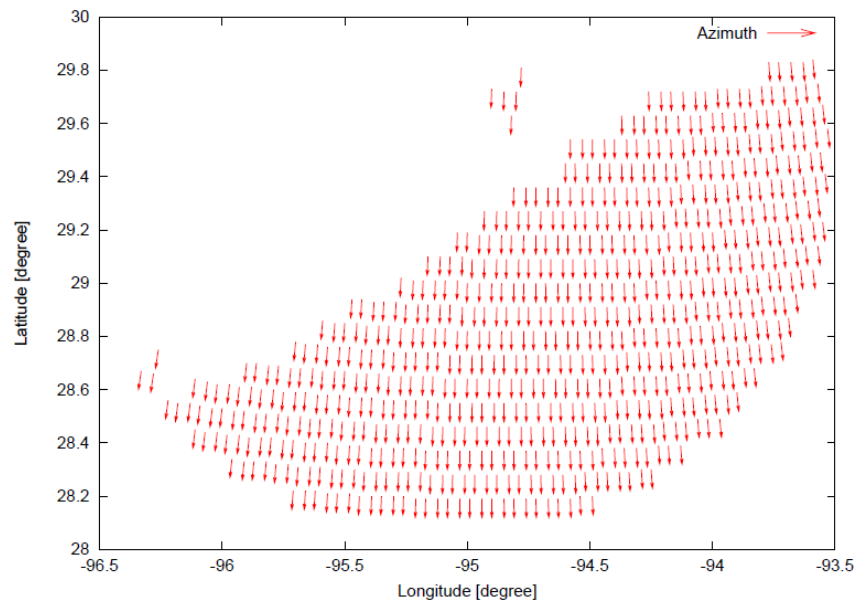

Fig. 6. Line of Sight Directions of AMSR-E.

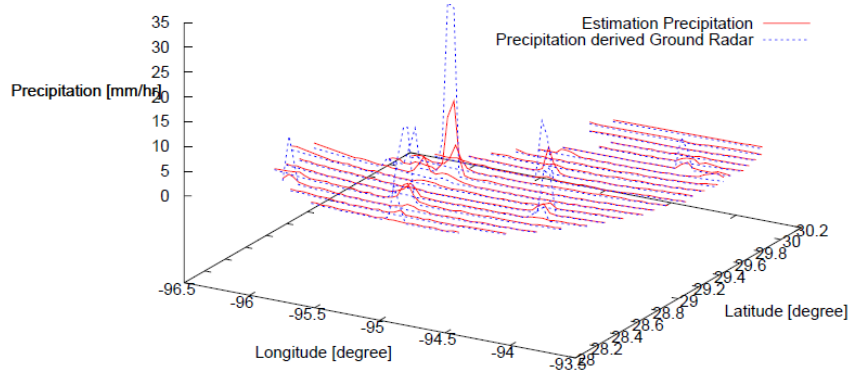

Fig. 7. Distribution of Actual Precipitation (Solid Line) and Estimated Precipitation (Doted Line) with Scattering Due to Ice Particles based on Assumption of mean Ice Particles Altitude. Each Line Corresponds to Observation Scan. 
Therefore, since the estimation method based on this assumption includes all errors due to the falling speed of raindrops, etc.; it can be seen that valid evaluation is difficult. From Fig. 7, it can be seen that the distributions of the two precipitations are very similar, and the positions where the peaks of the precipitations appear coincide.

The validity of the assumption that the cause of the "shift" is the observation configuration was confirmed. Here, Fig. 5 shows the distributions of actual precipitation and ice particle scattering precipitation. The blue line is the distribution of actual precipitation $[\mathrm{mm} / \mathrm{hr}]$, and the red line is the distribution of ice particle scattered precipitation [mm / hr]. Each line corresponds to a scan of the observation.

Fig. 6 shows the horizontal observation direction of the microwave radiometer AMSR-E. Furthermore, Fig. 7 shows the distribution of actual precipitation and scattered precipitation of ice particles assuming the average height of ice particles. The blue line is the distribution of actual precipitation $[\mathrm{mm} / \mathrm{hr}$, and the red line is the distribution of ice particle scattered precipitation $[\mathrm{mm} / \mathrm{hr}]$. Each line corresponds to a scan of the observation.

\section{Consideration of Observation Configuration in Precipitation Estimation Method}

If the average height of the ice particles can be assumed or known, the deviation can be corrected for the observation position of the $89 \mathrm{GHz}$ data by using equation (2). In this study, as described above, the effect of the $18 \mathrm{GHz}$ data shift on the precipitation estimation accuracy is considered to be small, so it is not considered. Precipitation was estimated using the AMSR-E microwave radiometers at $18 \mathrm{GHz}$ and $89 \mathrm{GHz}$ when passing over the ground precipitation radars in Houston, July 2007 and Kwajalein, September 2007. At that time, the correction of the deviation by the observation configuration was added to the $89 \mathrm{GHz}$ data.

The specific procedure of consideration is shown below.

1) If the average ice particle height is unknown, estimate (assume) it by some method (this study uses the average ice particle height obtained in the previous section).

2) Calculate the deviation from the average height of ice particles, the incident angle of observation, the azimuth, etc.

3) Correct the deviation corresponding to the latitude and longitude information of the $89 \mathrm{GHz}$ data.

Also, when calculating equation (3), $18 \mathrm{GHz}$ data and 89 $\mathrm{GHz}$ data at the same position are obtained, but their observation positions are shifted. Originally, all $89 \mathrm{GHz}$ data within the $18 \mathrm{GHz}$ footprint should be used. However, when all the data in the footprint is used, even if the antenna pattern is taken into consideration, the effect of the correction of the position is hardly seen because the data is smoothed in the footprint. Therefore, if it is desired to correct the $89 \mathrm{GHz}$ position effectively, it is better to use the nearest neighbor.

Therefore, in this study, the nearest $89 \mathrm{GHz}$ data was used based on the position of the $18 \mathrm{GHz}$ data. The precipitation estimated by these methods is called the estimated precipitation. Estimated precipitation and actual precipitation (surface precipitation measured by ground precipitation radar, etc.) were compared, and the correlation coefficient with Root Mean Square Error: RMSE was calculated.

$\mathrm{RMSE}=\sqrt{\frac{1}{N} \sum_{N}\left(P_{t}-P_{c}\right)^{2}}$

RMSE of precipitation estimation for before correction (solid line) and after correction (Doted line) as a function of mean precipitation (Houston data) is shown in Fig. 8.

Also, RMSE of precipitation estimation for before correction (solid line) and after correction (Doted line) as a function of mean precipitation (Kwajalein data) is shown 9 in Fig. 9.

The results are shown in Table III (Houston) and Table IV (Kwajalein). In the table, the number of data indicates the number of AMSR-E constant areas for which precipitation was estimated, and $\mathrm{Rt}$ and $\mathrm{Re}$ are the precipitation $(\mathrm{mm} / \mathrm{hr}$ ) and the estimated precipitation ( $\mathrm{mm} / \mathrm{hr}$ ), respectively, from the ground-based precipitation radar. Is shown. RMSE indicates the mean square error of both, and $\mathrm{R}$ indicates the correlation coefficient of both. The horizontal axis shows the actual rainfall in the observation area, and the vertical axis shows the RMSE of each data. Fig. 8 (Houston) and Fig. 9 (Kwajalein) show the relationship between average precipitation and RMSE.

Fig. 10 (Houston) and Fig. 11 (Kwajalein) show the average actual precipitation in the observation area on the horizontal axis and the correlation coefficient of each data on the vertical axis.

Fig. 8 shows the RMSE before correction (red) and after correction (green) of each observation data in Houston. The horizontal axis represents the average precipitation [mm $/ \mathrm{hr}]$ of each data, and the vertical axis represents the RMSE [mm / $\mathrm{hr}$ ] of the actual precipitation and the estimated precipitation. Fig.9 shows the RMSE of each observation data before correction (red) and after correction (green) at Kwajalein. The notation is the same as in the Houston diagram.

From Fig. 8, Fig. 9, Fig. 10 and Fig. 11, it can be seen that the RMSE is reduced and the correlation coefficient is increased by correcting the displacement. Therefore, it was confirmed that the accuracy of precipitation estimation was improved by the displacement correction. When the precipitation is relatively small, no improvement in accuracy is seen. Rain clouds with low precipitation are not sufficiently developed to produce ice particles, and thus the ice particles themselves may not be present. Moreover, it is difficult to estimate the average height of ice particles because the characteristics of the distribution of precipitation are not remarkable in a small amount of rain. For these reasons, the accuracy improvement when the precipitation is relatively small is considered to be insignificant.

Fig. 10 shows the correlation of each observation data in Houston before (red) and after (green). The horizontal axis is the average precipitation [mm / hr] of each data, and the vertical axis is the correlation coefficient between the actual precipitation and the estimated precipitation. Fig. 11 shows the correlation of each observation data at Kwajalein before (red) and after (green). The notation is the same as in the Houston diagram. 


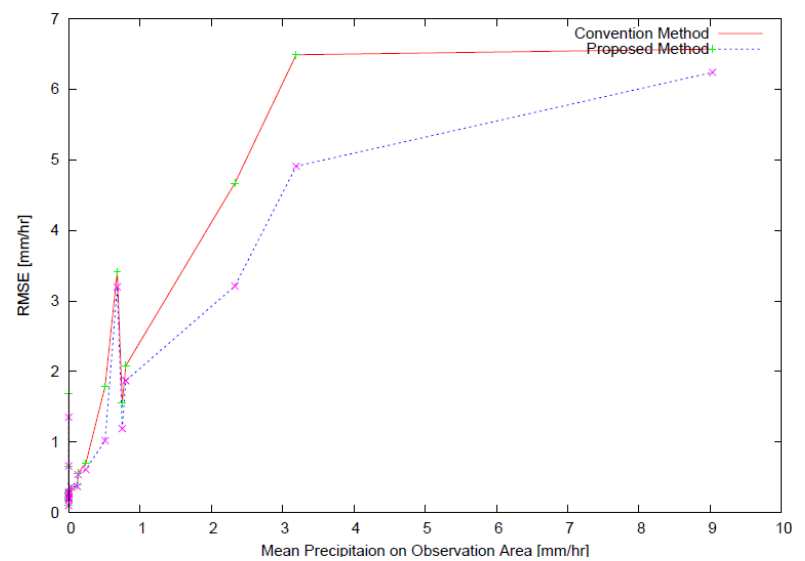

Fig. 8. Root Mean Square Error: RMSE of Precipitation Estimation for before Correction (Solid Line) and after Correction (Doted Line) as a Function of mean Precipitation (Houston Data).

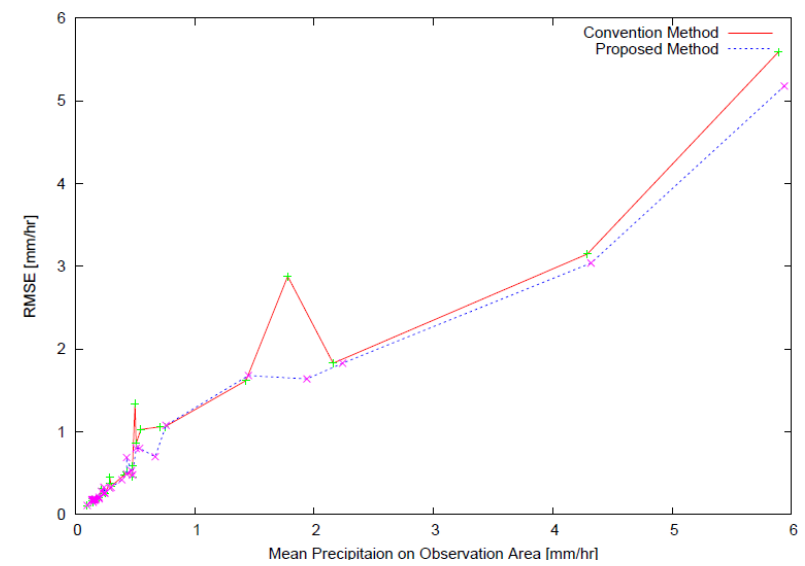

Fig. 9. Root Mean Square Error: RMSE of Precipitation Estimation for before Correction (Solid Line) and after Correction (Doted Line) as a Function of mean Precipitation (Kwajalein Data).

TABLE. III. RESULTS FROM PRECIPITATION ESTIMATION WITH/WITHOUT LOCATION DiSPLACEMENT CORRECTION (HOUSTON DATA)

\begin{tabular}{|c|c|c|c|c|c|c|c|c|c|c|c|}
\hline \multirow[b]{2}{*}{ Data No. } & \multirow[b]{2}{*}{ Date } & \multirow[b]{2}{*}{ No.of Data } & \multicolumn{3}{|c|}{ Conventional Method } & \multirow[b]{2}{*}{$\mathbf{R}$} & \multicolumn{2}{|c|}{ Proposed Method } & \multirow[b]{2}{*}{$\operatorname{Re}(\mathbf{m m} / \mathbf{h r})$} & \multirow[b]{2}{*}{ RMSE(mm/hr) } & \multirow[b]{2}{*}{$\mathbf{R}$} \\
\hline & & & $\mathbf{R t}(\mathbf{m m} / \mathbf{h r})$ & $\operatorname{Re}(\mathbf{m m} / \mathbf{h r})$ & RMSE(mm/hr) & & $\mathbf{H}(\mathbf{k m})$ & $\mathbf{R t}(\mathbf{m m} / \mathbf{h r})$ & & & \\
\hline 1 & $7 / 2$ & 676 & 0.24 & 0.4 & 0.7 & 0.42 & 14 & 0.25 & 0.38 & 0.61 & 0.61 \\
\hline 2 & $7 / 4$ & 627 & 9.03 & 7.85 & 6.57 & 0.69 & 10.5 & 9.01 & 7.19 & 6.24 & 0.75 \\
\hline 3 & $7 / 5$ & 599 & 0.51 & 0.3 & 1.79 & 0.38 & 3.5 & 0.36 & 0.29 & 1.02 & 0.47 \\
\hline 4 & $7 / 6$ & 741 & 0.8 & 0.87 & 2.08 & 0.5 & 13.5 & 0.79 & 0.82 & 1.87 & 0.64 \\
\hline 5 & $7 / 7$ & 1032 & 0 & 0.22 & 0.26 & N/A & 0 & 0 & 0.22 & 0.26 & N/A \\
\hline 6 & $7 / 7$ & 541 & 0 & 0.2 & 0.22 & N/A & 0 & 0 & 0.2 & 0.22 & N/A \\
\hline 7 & $7 / 9$ & 661 & 0 & 0.16 & 0.19 & N/A & 0 & 0 & 0.16 & 0.19 & N/A \\
\hline 8 & $7 / 9$ & 562 & 0 & 0.17 & 0.19 & N/A & 0 & 0 & 0.17 & 0.19 & N/A \\
\hline 9 & $7 / 11$ & 730 & 0 & 0.09 & 0.1 & N/A & 0 & 0 & 0.09 & 0.1 & N/A \\
\hline 10 & $7 / 12$ & 730 & 0 & 0.17 & 0.18 & N/A & 0 & 0 & 0.17 & 0.18 & N/A \\
\hline 11 & $7 / 13$ & 638 & 0 & 0.14 & 0.18 & N/A & 0 & 0 & 0.14 & 0.18 & N/A \\
\hline 12 & $7 / 14$ & 574 & 0 & 0.22 & 0.29 & N/A & 0 & 0 & 0.22 & 0.29 & N/A \\
\hline 13 & $7 / 16$ & 793 & 0.03 & 0.19 & 0.34 & 0.46 & 6 & 0.02 & 0.19 & 0.36 & 0.45 \\
\hline 14 & $7 / 16$ & 543 & 0 & 0.18 & 0.21 & N/A & 0 & 0 & 0.18 & 0.21 & N/A \\
\hline 15 & $7 / 18$ & 450 & 3.19 & 2.2 & 6.49 & 0.37 & 19 & 3.77 & 2.61 & 4.91 & 0.7 \\
\hline 16 & $7 / 20$ & 627 & 0.12 & 0.3 & 0.39 & 0.49 & 11 & 0.12 & 0.28 & 0.37 & 0.54 \\
\hline 17 & $7 / 21$ & 628 & 0 & 0.26 & 0.28 & N/A & 0 & 0 & 0.26 & 0.28 & N/A \\
\hline 18 & $7 / 22$ & 684 & 0 & 0.21 & 0.26 & N/A & 0 & 0 & 0.21 & 0.26 & N/A \\
\hline 19 & $7 / 23$ & 1091 & 0 & 0.41 & 0.65 & 0.36 & 12.5 & 0.01 & 0.44 & 0.66 & 0.35 \\
\hline 20 & $7 / 23$ & 543 & 0 & 0.14 & 0.18 & N/A & 0 & 0 & 0.14 & 0.18 & N/A \\
\hline 21 & $7 / 25$ & 676 & 0.13 & 0.5 & 0.56 & 0.64 & 8 & 0.13 & 0.49 & 0.54 & 0.66 \\
\hline 22 & $7 / 25$ & 471 & 0.75 & 0.55 & 1.55 & 0.65 & 11.5 & 0.6 & 0.46 & 1.19 & 0.65 \\
\hline 23 & $7 / 27$ & 684 & 2.33 & 2.94 & 4.67 & 0.6 & 17.5 & 2.44 & 3.08 & 3.21 & 0.84 \\
\hline 24 & $7 / 27$ & 712 & 0 & 1.06 & 1.69 & 0.16 & 0.5 & 0 & 0.9 & 1.35 & 0.18 \\
\hline 25 & $7 / 28$ & 720 & 0.68 & 0.53 & 3.41 & 0.18 & 2 & 0.66 & 0.44 & 3.2 & 0.21 \\
\hline 26 & $7 / 30$ & 568 & 0 & 0.16 & 0.19 & N/A & 0 & 0 & 0.16 & 0.19 & N/A \\
\hline
\end{tabular}


TABLE. IV. RESUltS From PreCIPITATION ESTIMATION WITH/WITHOUT LOCATION DiSPLACEMENT CORRECTION (KWAJALEIN DATA)

\begin{tabular}{|c|c|c|c|c|c|c|c|c|c|c|c|}
\hline \multirow[b]{2}{*}{ Data No. } & \multirow[b]{2}{*}{ Date } & \multirow[b]{2}{*}{ No.of Data } & \multicolumn{3}{|c|}{ Conventional Method } & \multirow[b]{2}{*}{$\mathbf{R}$} & \multicolumn{2}{|c|}{ Proposed Method } & \multirow[b]{2}{*}{$\operatorname{Re}(\mathbf{m m} / \mathbf{h r})$} & \multirow[b]{2}{*}{ RMSE(mm/hr) } & \multirow[b]{2}{*}{$\mathbf{R}$} \\
\hline & & & $\mathbf{R t}(\mathbf{m m} / \mathbf{h r})$ & $\operatorname{Re}(\mathbf{m m} / \mathrm{hr})$ & RMSE(mm/hr) & & H(km) & $\operatorname{Rt}(\mathbf{m m} / \mathbf{h r})$ & & & \\
\hline 1 & $9 / 1$ & 931 & 0.75 & 0.56 & 1.06 & 0.61 & 11.6 & 0.77 & 0.56 & 0.98 & 0.68 \\
\hline 2 & $9 / 1$ & 939 & 0.29 & 0.12 & 0.38 & 0.66 & 8.6 & 0.29 & 0.12 & 0.32 & 0.76 \\
\hline 3 & $9 / 3$ & 909 & 0.51 & 0.36 & 0.86 & 0.51 & 9 & 0.51 & 0.36 & 0.8 & 0.58 \\
\hline 4 & $9 / 3$ & 1146 & 0.5 & 0.12 & 1.34 & 0.18 & 15.8 & 0.43 & 0.12 & 0.69 & 0.48 \\
\hline 5 & $9 / 4$ & 1070 & 0.14 & 0 & 0.17 & 0.12 & 11.2 & 0.14 & 0 & 0.17 & 0.12 \\
\hline 6 & $9 / 5$ & 902 & 0.22 & 0.11 & 0.32 & 0.37 & 12.2 & 0.21 & 0.12 & 0.27 & 0.56 \\
\hline 7 & $9 / 5$ & 174 & 0.29 & 0.1 & 0.45 & 0.49 & 13.4 & 0.24 & 0.1 & 0.35 & 0.7 \\
\hline 8 & $9 / 6$ & 404 & 0.2 & 0.01 & 0.21 & 0.2 & 2.6 & 0.2 & 0.01 & 0.21 & 0.21 \\
\hline 9 & $9 / 6$ & 1041 & 0.17 & 0 & 0.19 & N/A & 0 & 0.17 & 0 & 0.19 & N/A \\
\hline 10 & $9 / 8$ & 919 & 0.48 & 0.13 & 0.46 & 0.73 & 3 & 0.48 & 0.13 & 0.48 & 0.75 \\
\hline 11 & $9 / 10$ & 1002 & 0.55 & 0.42 & 1.03 & 0.7 & 9.8 & 0.54 & 0.42 & 0.8 & 0.82 \\
\hline 12 & $9 / 12$ & 897 & 0.24 & 0 & 0.27 & 0.3 & 17.2 & 0.24 & 0 & 0.26 & 0.29 \\
\hline 13 & $9 / 12$ & 956 & 0.16 & 0 & 0.17 & 0.16 & 2.8 & 0.16 & 0 & 0.17 & 0.1 \\
\hline 14 & $9 / 13$ & 1018 & 0.15 & 0.03 & 0.17 & 0.6 & 4.6 & 0.15 & 0.03 & 0.17 & 0.59 \\
\hline 15 & $9 / 13$ & 1231 & 0.17 & 0.02 & 0.18 & 0.22 & 8 & 0.17 & 0.02 & 0.19 & 0.22 \\
\hline 16 & $9 / 15$ & 1045 & 4.29 & 2.66 & 3.15 & 0.83 & 5.8 & 4.32 & 2.66 & 3.04 & 0.85 \\
\hline 17 & $9 / 15$ & 958 & 0.48 & 0.22 & 0.59 & 0.65 & 10.4 & 0.47 & 0.22 & 0.53 & 0.71 \\
\hline 18 & $9 / 17$ & 936 & 0.25 & 0 & 0.26 & 0.07 & 7.2 & 0.25 & 0 & 0.26 & 0.08 \\
\hline 19 & $9 / 19$ & 1000 & 5.89 & 2.84 & 5.59 & 0.7 & 15.2 & 5.94 & 2.84 & 5.18 & 0.79 \\
\hline 20 & $9 / 20$ & 1071 & 2.18 & 1.36 & 1.83 & 0.9 & 12.2 & 1.94 & 0.94 & 1.64 & 0.89 \\
\hline 21 & $9 / 21$ & 992 & 0.14 & 0.05 & 0.19 & 0.4 & 8.4 & 0.14 & 0.05 & 0.18 & 0.53 \\
\hline 22 & $9 / 22$ & 1003 & 1.43 & 0.72 & 1.62 & 0.71 & 9 & 1.45 & 0.72 & 1.68 & 0.72 \\
\hline 23 & $9 / 22$ & 1042 & 0.16 & 0.04 & 0.18 & 0.38 & 10.2 & 0.16 & 0.04 & 0.18 & 0.41 \\
\hline 24 & $9 / 24$ & 966 & 0.2 & 0.04 & 0.2 & 0.59 & 3.4 & 0.2 & 0.04 & 0.19 & 0.6 \\
\hline 25 & $9 / 26$ & 945 & 0.3 & 0.04 & 0.34 & 0.48 & 13 & 0.3 & 0.04 & 0.33 & 0.55 \\
\hline 26 & $9 / 26$ & 723 & 0.71 & 0.41 & 1.06 & 0.69 & 11 & 0.67 & 0.41 & 0.7 & 0.84 \\
\hline 27 & $9 / 28$ & 1130 & 0.43 & 0.12 & 0.52 & 0.63 & 10 & 0.43 & 0.12 & 0.49 & 0.69 \\
\hline 28 & $9 / 28$ & 936 & 0.41 & 0.13 & 0.48 & 0.62 & 9.2 & 0.38 & 0.13 & 0.42 & 0.73 \\
\hline 29 & $9 / 29$ & 381 & 0.15 & 0 & 0.15 & N/A & 0 & 0.15 & 0 & 0.15 & N/A \\
\hline 30 & $9 / 29$ & 915 & 0.1 & 0 & 0.11 & N/A & 0 & 0.1 & 0 & 0.11 & N/A \\
\hline 31 & $9 / 30$ & 204 & 1.78 & 0.52 & 2.88 & 0.33 & 20 & 2.24 & 1 & 1.83 & 0.8 \\
\hline
\end{tabular}

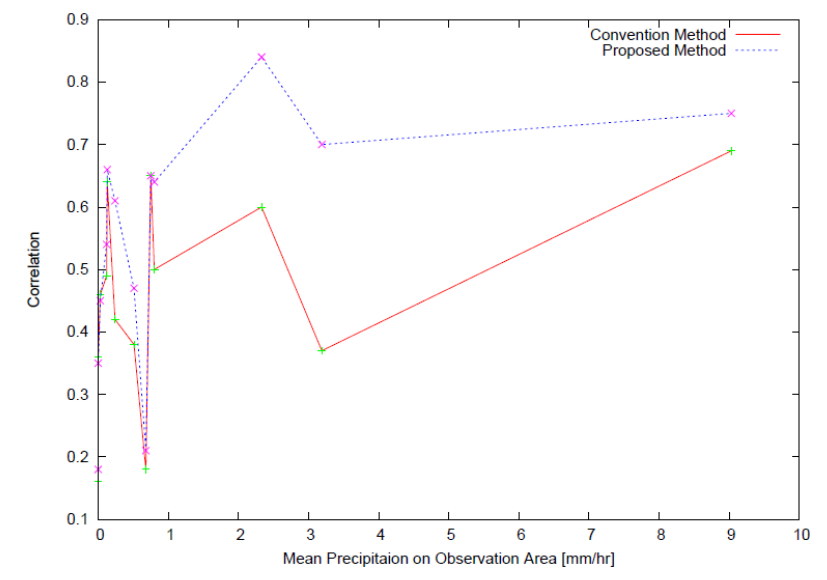

Fig. 10. Correlation Coefficient between Actual and Estimated Precipitation for before Correction (Solid Line) and after Correction (Doted Line) as a Function of mean Precipitation (Houston Data).

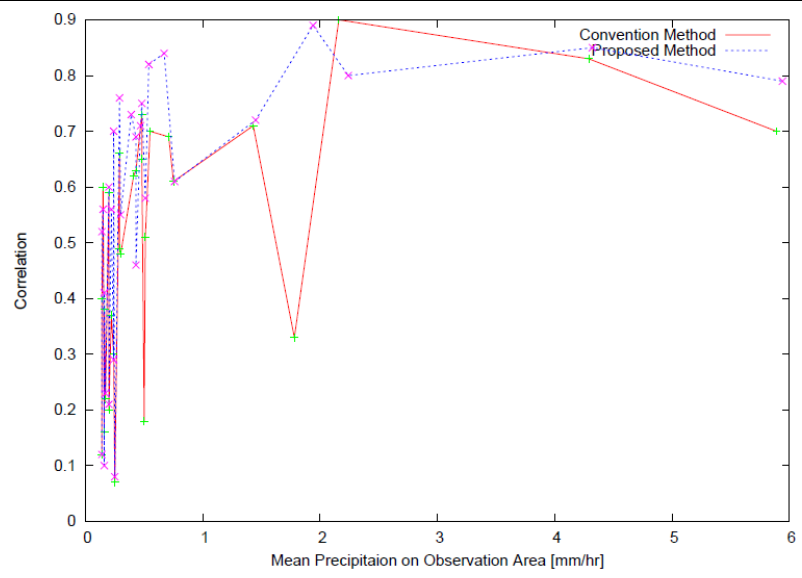

Fig. 11. Correlation Coefficient between Actual and Estimated Precipitation for before Correction (Solid Line) and after Correction (Doted Line) as a Function of mean Precipitation (Kwajalein Data). 
Fig. 12 shows the Houston race on January 10, 2008. Indicates precipitation. Fig. 13 shows the precipitation estimated using AMSR-E data. On January 10th, heavy rainfall was observed locally, and convective clouds are thought to have occurred. Using the AMSR-E data on that day, the average ice crystal height was estimated to be $11 \mathrm{~km}$. The RMSE was improved from $8.16 \mathrm{~mm} / \mathrm{hr}$ to $6.57 \mathrm{~mm} / \mathrm{hr}$ by the proposed method considering the ice crystal height with respect to the precipitation estimated by the conventional method, and the correlation coefficient was increased from 0.51 to 0.73 .

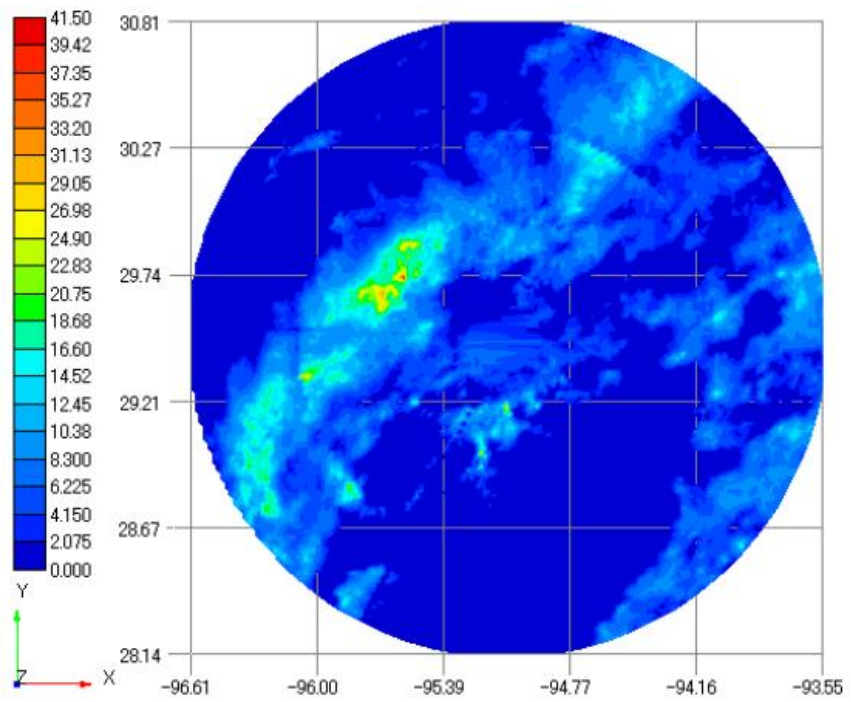

Fig. 12. Rainfall Rate Derived from Rain Radar which is Situated in Houston Measured on January 102008.

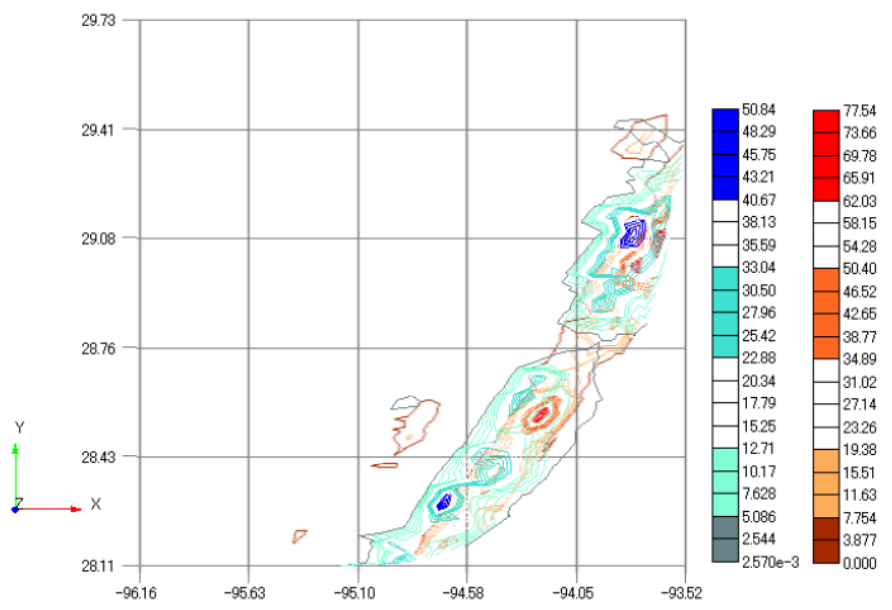

Fig. 13. Estimated Rainfall Rate with AMSR-E Data of Houston which is acquired on January 102008.

\section{CONCLUSION}

The method of considering the geometrical relationship between the observation target ice particles and the microwave radiometer in rainfall estimation was shown, and its validity was shown by comparing it with precipitation radar data on the ground. Observation objects that exist at high altitudes, such as ice particles, have a large difference between the observation point projected on the ground surface and the position of the upper troposphere where the observation object exists did. This effect was insignificant when the precipitation was small because ice particles were often absent, but the effect was significant when the precipitation was large.

In other words, the proposed method is effective and effective for AMSR data in Houston, which was shown as an example of a highly developed convective rain cloud with an ice cloud at the top. In the case of Kwajalein, the effect is insignificant. In addition, the proposed method requires an assumption of ice particle height, and it is necessary to make assumptions based on climatic values. In addition, microwaves in the $89 \mathrm{GHz}$ band, which are considered to be sensitive to ice particles, are not only sensitive to ice particles, so it must be taken into account that they are also affected by the presence of non-ice particles.

The proposed method works well for rainfall rate estimation with the AMSR and AMSR-E data.

\section{FutURE RESEARCH WORKS}

In this study, rainfall was estimated considering the geometric relationship between the observation target and the microwave radiometer. However, it takes a certain amount of time for an object at a high altitude to change (affect) the physical quantity on the ground surface. Therefore, when observing a fluctuating rain, it is necessary to consider this time difference. When observing very local and rapidly changing phenomena, such as cumulonimbus clouds, it is necessary to consider the spatial and temporal lags due to their observation configurations in order to perform more precise observations.

\section{ACKNOWLEDGMENT}

The author would like to thank Dr. Kenta Azuma of former student of Saga University and Prof. Dr. Hiroshi Okumura of Saga University for his valuable comments and suggestions.

\section{REFERENCES}

[1] Roy W.Spencer and H.M ichael Goodman and Robbir E.Hood, Precipitation Retrieval over Land and Ocean with the SSM/I : Identification and Characteristics of the Scattering Signal,Journal of Atmospheric and ocean technology, vol.6, 254-273, April, 1989.

[2] Guosheng Liu and Judith A.Curry,Retrieval of Precipitation from Satellite Microwave Measurement Using Both Emission and Scattering, Journal of Geophysical reseach, vol.97, no.D9, 9959-9974, June 20, 1992.

[3] Guosheng Liu and Judith A.Curry and Rong- Shyang Sheu, Classification of cloud over the western equatorial Pacific Ocean using combined infrared and microwave satellite data,Journal of Geophysical reseach, vol.100, no.D7, 13, 811-13, 826, July 20, 1995.

[4] Guosheng Liu,Description Precipitation Retrieval Algorithm for ADEOS II AMSR, http://sharaku.eorc.jaxa.jp/AMSR/doc/alg/7 alg.pdf,2002.

[5] Roberti, L., Haferman J., and Kummerow C. Microwave radiative transfer through horizontally inhomogeneous precipitating clouds. Journal Of Geophysical Research. 99, 16, 707-16, 718. (1994).

[6] Kummerow, C., P.Poyner, W.Berg and J. Thomas-Stahle, The E $\square$ ects of Rainfall Inhomogeneity on Climate Variability of Rainfall stimated from Passive Microwave Sensors, JAOTEC, 21, 624-638, 2004.

[7] Takao Takeda, Science of Water Cycle-Behavior of Clouds-Tokyodo Shuppan、 1987. 
[8] Kohei Arai, T. Igarashi and C. Ishida, Evaluation of MOS-1 Microwave Scanning Radiometer(MSR) data in field experiments, Proc. of the 18th International Symposium on Remote Sensing of Environment, 1-8, 1984.

[9] Y. Itoh, K. Tachi, Y. Sato and Kohei Arai, Advanced Microwave Scanning Radiometer: AMSR, Preliminary study, Proc. of the IGARSS'89, I1-4, 273-276, 1989.

[10] K. Tachi, Kohei Arai and Y. Satoh, Advanced Microwave Scanning Radiometer -Requirements and Preliminary Design Study-, IEEE Trans. on Geoscience and Remote Sensing, Vol.27, No.2, pp.177-183, Jan.1989.

[11] Kohei Arai and K. Teramoto, Antenna Pattern Correction and SST Estimation Algorithms for AMSR Proceedings of the AMSR Science Workshop, (1997).

[12] Kohei Arai, Advanced Microwave Scanning Radiometer(AMSR) Proceedings of the AMSR Science Workshop Tokyo, Japan, 1997.

[13] Kohei Arai and Jun Sakakibara, Simultaneous estimation of sea surface temperature, wind speed and water vapor with AMSR-E data based on improved simulated annealing, Proceedings of the Renewable Energy Resources Symposium, 00547, 2006.

[14] M. Konda, A. Shibata, N. Ebuchi and Kohei Arai, Correction of the effect of relative wind direction on wind speed derived by AMSR, Journal of Oceanography, 64, 395-404, 2006.

[15] Kohei Arai, Kenta Azuma, Precipitation estimation using AMSR data considering geometric relationship between observation target and radiometer, 49,1,32-40,2010.

[16] Kohei Arai, Nonlinear Optimization Based Sea Surface Temperature: SST Estimation Methods with Remote Sensing Satellite Based Microwave Scanning Radiometer: MSR Data, International Journal of Research and Reviews in Computer Science (IJRRCS) Vol. 3, No. 6, 1881-1886, December 2012, ISSN: 2079-2557, 2012.

[17] Kohei Arai, X.Liang, Q.Liu, Method for estimation of rain rate with Rayleigh and Mie scattering assumptions on the Z-R relationship for different rainfall types, Advances in Space Research, 36, 5, 813-817, 2005.

[18] Kohei Arai, Comparison between Rayleigh and Mie scattering assumptions for Z-R relation and rainfall rate estimation with TRMM/PR data, International Journal of Advanced Research in Artificial Intelligence, 2, 8, 1-6, 2013.

[19] Arai,K., Detecting Algorithm for Rainfall Area Movement based on Kalman Filtering, Proceedings of the NSAT/SWT Symposium, Kyoto, Nov. 1995.

[20] Kohei Arai and Masanori Saka, Reconstruction of cross section of rainfall situations with precipitation radar data based on wavelet analysis, Abstracts of the 35th Congress of the Committee on Space Research of the ICSU, A1.1-0232-04, (2004).

\section{AUTHOR's PROFILE}

Kohei Arai, He received BS, MS and PhD degrees in 1972, 1974 and 1982, respectively. He was with The Institute for Industrial Science and Technology of the University of Tokyo from April 1974 to December 1978 also was with National Space Development Agency of Japan from January, 1979 to March, 1990. During from 1985 to 1987, he was with Canada Centre for Remote Sensing as a Post Doctoral Fellow of National Science and Engineering Research Council of Canada. He moved to Saga University as a Professor in Department of Information Science on April 1990. He was a councilor for the Aeronautics and Space related to the Technology Committee of the Ministry of Science and Technology during from 1998 to 2000 . He was a councilor of Saga University for 2002 and 2003. He also was an executive councilor for the Remote Sensing Society of Japan for 2003 to 2005 . He is an Adjunct Professor of University of Arizona, USA since 1998. He also is Vice Chairman of the Science Commission "A" of ICSU/COSPAR since 2008 then he is now award committee member of ICSU/COSPAR. He wrote 37 books and published 570 journal papers. He received 30 of awards including ICSU/COSPAR Vikram Sarabhai Medal in 2016, and Science award of Ministry of Mister of Education of Japan in 2015. He is now Editor-in-Chief of IJACSA and IJISA. http://teagis.ip.is.saga-u.ac.jp/index.html. 